\title{
Epidemiological studies of diabetes mellitus in Denmark: 6. Use of hospital services by insulin-treated diabetic patients
}

\author{
A. Green ${ }^{1}$ and F. Solander ${ }^{2}$ \\ ${ }^{1}$ University Institute of Clinical Genetics and ${ }^{2}$ The Funen County Medical Computing Department, Odense, Denmark
}

Summary. The use of hospital services among insulin-treated diabetic patients was studied in a group of 1499 patients, representing $>98 \%$ of all prevalent cases as of 1 July 1973 in the Funen County, Denmark, who were followed during a $8 \frac{1}{2}$ year period by a record linkage with the regional computerized hospital registration system. On the prevalence date, $26 \%$ of the patients (in the age group 0-9 years: $74 \%$ ) attended a diabetic outpatient clinic. The overall average admission rates for males and females were 0.46 and 0.53 per diabetes-year, re- spectively, and the average estimated 'hospital bed-day occupancy' rates per diabetes-year were 7.2 and 9.6, respectively. These figures are five times higher than expected from the general population. Diabetes was not recorded as a discharge diagnosis (primary and/or secondary) in 13\% of the male and $15 \%$ of the female 'hospital bed-day occupancy' rate.

Key words: Insulin-treated diabetes mellitus, epidemiology, public health.
As diabetes mellitus represents a major public health problem, information on the use of hospital services by diabetic patients is needed for planning and evaluation of a diabetes health care system. Only a few reports on the hospitalization patterns of diabetes have been published. In Denmark, it has been estimated that $2 \%$ of the total number of hospital days used annually are patients who had diabetes as the primary diagnosis at discharge [1]. In the United States, it has recently been assessed that the total direct costs for all admissions of insulindependent diabetic patients aged $<30$ years were $\$ 530,000$ per year in a population of approximately half a million inhabitants [2].

Among outpatient diabetic subjects, a considerable reduction in the hospital admission rate and length of inpatient stay has been reported after the establishment of specialized diabetes care centres [3-5], but detailed information on the use of hospital services in the general diabetic population is not available.

In this report we describe the hospitalization pattern among insulin-treated Danish diabetic patients, assessed from a follow-up study of a total populationbased patient group [6].

\section{Materials and methods}

\section{The study region}

The Funen County, Denmark, has approximately 450,000 inhabitants and comprises a geographically well-delineated and demographically representative $9 \%$ sample of total Denmark. The region has its own health care system, organized and paid for by the public, including one university hospital (with a children's department and three internal medical departments), four hospitals with separate internal medical and surgical departments and four small hospitals with mixed medical and surgical wards. All medical departments have their own diabetic outpatient clinics. In Denmark there are no officially established guidelines on how to run outpatient clinics, and local factors determine whether the diabetic patients are supervised by their general practitioner or by the nearest hospital clinic. The patients may be referred to hospital by their general practitioner, the outpatient clinic, or the emergency rooms at the hospitals.

\section{The study material}

Using insulin prescriptions, $>98 \%$ of the prevalent (cross-sectional) population of insulin-treated diabetic patients in the Funen County as of 1 July 1973 were ascertained as described previously [6].

Information on attendance at a diabetic clinic as of the prevalence date (defined as notified appointment of visits before and after this date) was available from the medical records scrutinized when collecting clinical data on the patients. Data on all admissions (not including admissions to psychiatric departments) of the patients during the period 1 July 1973-31 December 1981 were obtained by a record linkage with the hospital register in the Funen County Medical Computing Department which contains data on all hospital admissions.

For each patient the number of diabetes-months observed until date of death, the date of moving out of the region, or, at latest 31 December 1981 were calculated; these numbers were accumulated within age and sex groups and transformed to estimate the number of observed diabetes-years within each group. The use of hospital services was expressed as the "hospital bed-day occupancy", i.e. the recorded number of hospital days divided by the number of diabetes-years observed; this index may be interpreted as the number of hospital days an insulin-treated diabetic patient (specified to age and sex) will use per year. 
Table 1. The prevalent population of insulin-treated diabetic patients in the Funen County, Denmark as of 1 July 1973, followed from 1 July 1973-31 December 1981

\begin{tabular}{lrc}
\hline & Males & Females \\
\hline $\begin{array}{l}\text { No. of subjects studied } \\
\begin{array}{l}\text { No. of subjects attending a diabetic } \\
\text { clinic as of 1 July 1973 }\end{array}\end{array}$ & 783 & 716 \\
$\begin{array}{l}\text { No. of diabetes-months observed } \\
\text { during follow-up period }\end{array}$ & 64808 & 58721 \\
$\begin{array}{l}\text { No. of recorded admissions } \\
\text { during follow-up period }\end{array}$ & 2515 & 2612 \\
$\begin{array}{l}\text { No. of 'hospital bed-days' occupied } \\
\text { during follow-up period }\end{array}$ & 38922 & 47075 \\
$\begin{array}{l}\text { No. of subjects with at least one recorded } \\
\text { admission during follow-up period }\end{array}$ & 627 & 616 \\
\hline
\end{tabular}

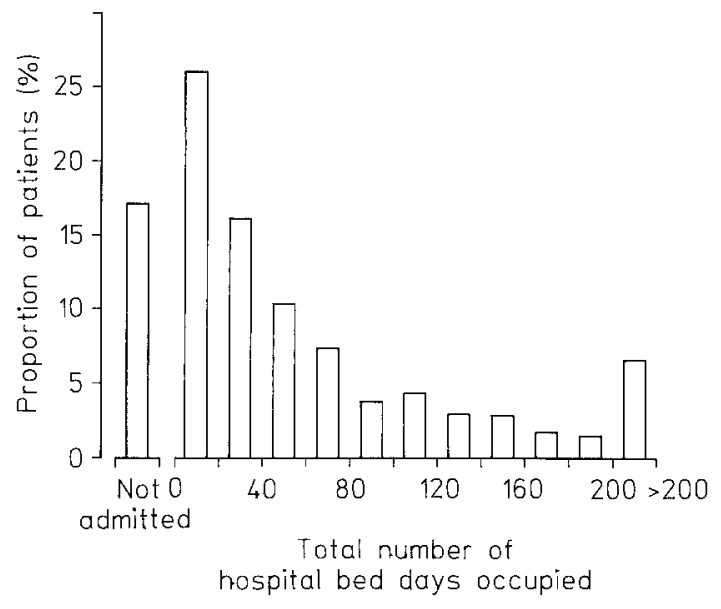

Fig. 1. Distribution of 'hospital bed-days' occupied during follow-up

Table 2. Attendance at a diabetic clinic as of 1 July 1973: distributed according to age and residence

\begin{tabular}{|c|c|c|c|c|c|c|c|c|c|}
\hline $\begin{array}{l}\text { Age as of } \\
1 \text { July } 1973 \\
\text { (years) }\end{array}$ & \multicolumn{3}{|c|}{$\begin{array}{l}\text { Residence in municipalities } \\
\text { of Odense, Svendborg, Nyborg, } \\
\text { Middelfart and Fåborg }\end{array}$} & \multicolumn{3}{|c|}{$\begin{array}{l}\text { Residence in the rest } \\
\text { of the county }\end{array}$} & \multicolumn{3}{|l|}{ Total } \\
\hline $0-9$ & 22 & 19 & 86 & 9 & 4 & 44 & 31 & 23 & 74 \\
\hline $10-19$ & 77 & 45 & 58 & 54 & 23 & 43 & 131 & 68 & 52 \\
\hline $20-29$ & 119 & 38 & 32 & 75 & 22 & 29 & 194 & 60 & 31 \\
\hline $50-59$ & 126 & 36 & 29 & 102 & 10 & 10 & 228 & 46 & 20 \\
\hline $60-69$ & 146 & 35 & 24 & 121 & 11 & 9 & 267 & 46 & 17 \\
\hline $70+$ & 132 & 29 & 22 & 105 & 14 & 13 & 237 & 43 & 18 \\
\hline Total & 872 & 291 & 33 & 627 & 105 & 17 & 1499 & 396 & 26 \\
\hline
\end{tabular}

a Each of the municipalities possesses a hospital with a department of internal medicine

\section{Results}

The number of subjects studied, the number of diabetes-months observed, and the numbers of hospital services recorded are shown in Table 1.

Table 2 shows in detail the pattern of attendance at a diabetic clinic. In total, $26 \%$ of the patients were attending a clinic on the prevalence date (1 July 1973); among patients aged $0-9$ years, the proportion was $74 \%$; it decreased to $18 \%$ among patients $\geqslant 70$ years. Within all age groups the proportion was higher among patients residing in areas possessing a hospital with a department of internal medicine compared with patients residing in rural areas.

Figure 1 shows the distribution of total number of 'hospital bed-days' occupied by the patients during the follow-up period. As there were no major differences between the distributions within sex and broad age groups, only the marginal distribution is presented. It is seen that $17 \%$ of the patients $(20 \%$ of the male and $14 \%$ of the female patients) had not been admitted at all, and $26 \%$ occupied a total of $<20$ 'hospital bed-days' during follow-up. Twenty per cent occupied $\geqslant 120$ 'hospital bed-days' (highest number recorded was 626 days). In the interpretation of Figure 1, it must be remembered that some of the patients had died or moved out of the study region before the end of the $81 / 2$ years follow-up period. This introduces a source of bias which has been taken into account in the following analysis.

During the follow-up period, the overall average admission rate was 0.46 and 0.53 per diabetes-year for males and females, respectively. The overall average 'hospital bed-day occupancy' was 7.2 and 9.6 days per diabetes-year. Figure 2 illustrates the age- and sex-specific patterns. When all ages were combined, $61 \%$ of the occupancy in males and 54\% in females represented admissions for which diabetes was recorded as the primary diagnosis at discharge; the proportion was highest in the younger age groups. In contrast, diabetes was not listed among the diagnoses at discharge for admissions representing $13 \%$ of the male and $15 \%$ of the female 'hospital bed-day occupancy'.

The use of 'hospital bed-days', with reference to age, sex and type of department, is specified in Table 3. In males and females (all age groups combined) $63 \%$ and $60 \%$, respectively, of the 'hospital bed-day occupancy' 
Table 3. 'Hospital bed-day occupancy' rates (estimated as number of hospital days per number of observed diabetes-years) by insulin-treated diabetic patients: distributed according to age, sex and type of department

\begin{tabular}{|c|c|c|c|c|c|c|c|c|c|c|c|}
\hline \multirow{3}{*}{$\begin{array}{l}\text { Age as of } \\
1 \text { July } 1973 \\
\text { (years) }\end{array}$} & \multicolumn{9}{|c|}{ Type of department } & & \\
\hline & \multicolumn{2}{|c|}{$\begin{array}{l}\text { Internal medicine } \\
\text { (including children) }\end{array}$} & \multicolumn{2}{|c|}{ Surgery } & \multirow{2}{*}{$\begin{array}{l}\text { Gynae- } \\
\text { cology/ } \\
\text { obstetrics }\end{array}$} & \multicolumn{2}{|l|}{ Mixed $^{\mathrm{a}}$} & \multicolumn{2}{|l|}{ Other } & \multicolumn{2}{|l|}{ Total } \\
\hline & Males & Females & Males & Females & & Males & Females & Males & Females & Males & Females \\
\hline $0-9$ & 3.61 & 8.00 & 0.03 & 0.06 & 0.00 & 0.14 & 0.00 & 0.07 & 0.08 & 3.85 & 8.14 \\
\hline $10-19$ & 2.55 & 2.65 & 0.76 & 0.49 & 2.07 & 0.11 & 0.02 & 0.25 & 0.03 & 3.67 & 5.26 \\
\hline $40-49$ & 4.56 & 3.36 & 1.55 & 0.64 & 0.23 & 0.60 & 0.54 & 0.43 & 0.67 & 7.14 & 5.44 \\
\hline $50-59$ & 5.06 & 5.20 & 3.39 & 1.30 & 0.10 & 0.58 & 0.97 & 0.47 & 0.56 & 9.50 & 8.13 \\
\hline $60-69$ & 7.36 & 8.25 & 2.99 & 3.12 & 0.06 & 1.01 & 1.71 & 0.34 & 0.37 & 11.70 & 13.51 \\
\hline $70+$ & 7.70 & 11.45 & 5.17 & 3.20 & 0.02 & 3.07 & 3.25 & 0.25 & 0.36 & 16.19 & 18.28 \\
\hline All & 4.51 & 5.78 & 1.76 & 1.62 & 0.77 & 0.57 & 1.08 & 0.36 & 0.37 & 7.21 & 9.62 \\
\hline
\end{tabular}

a Departments at small hospitals with mixed surgical and medical wards

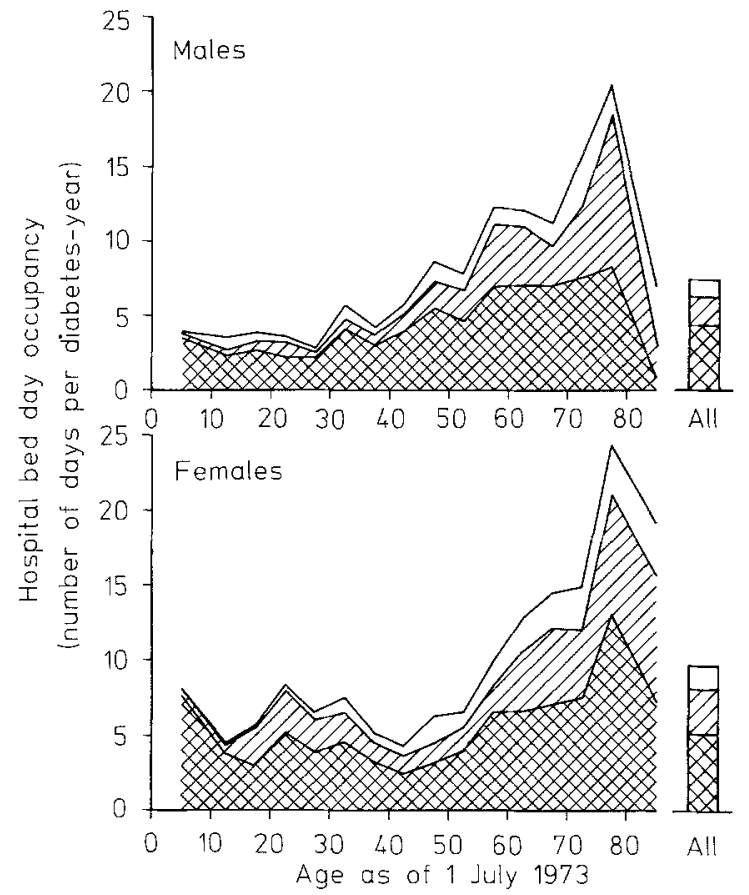

Fig. 2. Estimated 'hospital bed-day occupancy' rates according to sex, age and diagnosis at discharge. Upper line: total bed occupancy; middle line: bed occupancy with diabetes as primary and/or secondary diagnosis at discharge; lower line: bed occupancy with diabetes only as the primary diagnosis at discharge

represented admissions to medical departments (including sub-specialties); the proportion was especially high in the younger age groups. In females, $8 \%$ of the overall average bed occupancy represented admissions to gynaecological/obstetrical departments, but the proportion was $46 \%$ in the age group $20-29$ years.

The bed occupancy patterns were also analysed after classification of the patients according to attendance at a diabetic outpatient clinic on the prevalence date (Table 4). In general, there were no major differences
Table 4. 'Hospital bed-day occupancy' rates (estimated as number of hospital days per number of observed diabetes-years) by insulin-treated diabetic patients: distributed according to sex, age and attendance at a diabetic outpatient clinic

\begin{tabular}{|c|c|c|c|c|}
\hline \multirow{3}{*}{$\begin{array}{l}\text { Age as of } \\
1 \text { July } 1973 \\
\text { (years) }\end{array}$} & \multicolumn{4}{|c|}{ In attendance at a diabetic clinic as of 1 July 1973} \\
\hline & \multicolumn{2}{|l|}{ Yes } & \multicolumn{2}{|l|}{ No } \\
\hline & Males & Females & Males & Females \\
\hline $0-19$ & 3.59 & 5.60 & 3.88 & 5.97 \\
\hline $20-29$ & 3.09 & 7.11 & 3.21 & 7.84 \\
\hline $30-39$ & 4.28 & 8.76 & 4.63 & 4.53 \\
\hline $40-49$ & 6.61 & 6.87 & 7.30 & 5.00 \\
\hline $50-59$ & 10.45 & 11.30 & 9.30 & 7.10 \\
\hline $60-69$ & 10.53 & 16.01 & 11.95 & 13.05 \\
\hline $70+$ & 8.58 & 18.94 & 17.86 & 18.10 \\
\hline All & 5.82 & 9.80 & 7.72 & 9.55 \\
\hline
\end{tabular}

between the two groups in the various age and sex classes.

Using published statistics [1], we have compared the actual 'hospital bed-day occupancy' with that expected according to sex and broad age groups (Table 5). The overall observed/expected ratio was 4.9 and 6.5 for males and females, respectively, with a markedly increased trend as age increased.

\section{Discussion}

Our study is a complete follow-up of a total, population-based patient group which was ascertained at a well-defined point of time. We believe that our results provide a representative picture of the use of hospital services among insulin-treated diabetic patients in Denmark where no specialized diabetes care systems were organized by the health authorities during the study period.

The overall average 'hospital bed-day occupancy' rates reported here ( 7.2 and 9.6 hospital days per diabe- 
Table 5. Observed and expected 'hospital bed-day occupancy' rates (estimated as number of hospital days per number of observed diabetesyears) by insulin-treated diabetic patients: distributed according to age and sex

\begin{tabular}{|c|c|c|c|c|c|c|}
\hline \multirow{3}{*}{$\begin{array}{l}\text { Age as of } \\
1 \text { July } 1973 \\
\text { (years) }\end{array}$} & \multicolumn{6}{|c|}{ 'Hospital bed-day occupancy' rate } \\
\hline & \multicolumn{3}{|l|}{ Males } & \multicolumn{3}{|l|}{ Females } \\
\hline & Observed & Expected & $\begin{array}{l}\text { Observed/ } \\
\text { expected }\end{array}$ & Observed & Expected & $\begin{array}{l}\text { Observed/ } \\
\text { expected }\end{array}$ \\
\hline $1-14$ & 3.62 & 0.51 & 7.1 & 5.90 & 0.41 & 14.4 \\
\hline $15-44$ & 4.33 & 0.67 & 6.5 & 6.22 & 1.29 & 4.8 \\
\hline $75+$ & 16.61 & 6.90 & 2.4 & 22.00 & 7.74 & 2.8 \\
\hline All & 7.21 & 1.47 & 4.9 & 9.62 & 1.47 & 6.5 \\
\hline
\end{tabular}

${ }^{a}$ Estimated from published statistics [1]

tes-year for males and females, respectively) are higher than the value of 5.4 reported from Los Angeles before a reorganization of diabetes care [3]. However, our figures refer to a total patient population, whereas the Los Angeles figure refers only to patients attending a particular hospital clinic. In addition, the general differences in health care between Denmark and the United States make comparison difficult.

Several groups have reported a large reduction in bed occupancy after reorganization of diabetes care [3-5], and such reports are now under consideration by the Danish authorities. This is justified since only approximately $25 \%$ of the patients in our study were attending a diabetic clinic on the prevalence date, and of the diabetic children, only $75 \%$ were attending. The observed positive correlation between residence in an area possessing a hospital with a department of internal medicine and attendance at a diabetic clinic is so far unexplained; no systematical differences were found in the annual bed occupancy rates between patients who were or were not attending but the two patient groups might differ with regard to clinical characteristics.

Our analysis indicates that a substantial proportion (about 20\%) of the insulin-treated diabetic patients may be classified as having 'high bed-occupancy' rates, i.e. they were admitted for $\geqslant 120$ days during the follow-up period. On the other hand, about $45 \%$ were less demanding (no admissions or admitted for $<20$ days). This demonstrates the existence of considerable heterogeneity in our patient population. Unfortunately, due to legislation we were unable to link our clinical data for each patient with the register of hospital admissions, so we cannot characterize further subgroups of patients on a clinical basis.
The overall annual bed occupancy rate was five to six times higher than expected. Thus, $15 \%-20 \%$ of the bed occupancy was not related to diabetes and, correspondingly, $80 \%-85 \%$ could be attributed to diabetes. However, in admissions corresponding to only $55 \%-60 \%$ of the total bed occupancy, diabetes was recorded as the primary diagnosis on discharge. We conclude, therefore, that statistical analysis based solely on diabetes as the recorded primary diagnosis at discharge will underestimate the real magnitude of the use of hospital services by patients with diabetes.

\section{References}

1. Sundhedsstyrelsen (1981) Sygehusstatistik II: 31981 (,Sygdomsmønsteret ved somatiske sygehusafdelinger 1979"). Sundhedsstyrelsen, Copenhagen

2. Fischbein HA, Faich GA, Ellis SE (1982) Incidence and hospitalization patterns of insulin-dependent diabetes mellitus. Diabetes Care 5: 630-633

3. Miller LV, Goldstein J (1972) More efficient care of diabetic patients in a county-hospital setting. N Engl J Med 286: 1388-1391

4. Hardie J, McPherson K, Baum JD (1979) Hospital admission rates of diabetic children. Diabetologia 16: 225-228

5. Moffitt P, Fowler J, Eather G (1979) Bed occupancy by diabetic patients. Med J Aust 1: 244-245

6. Green A, Hauge M, Holm NV, Rasch LL (1981) Epidemiological studies of diabetes mellitus in Denmark. II. A prevalence study based on insulin prescriptions. Diabetologia 20:468-470

Received: 25 April 1983

and in revised form: 20 December 1983

Dr. Anders Green

University Institute of Clinical Genetics

J. B. Winsløwsvej 17

DK-5000 Odense C

Denmark 